\title{
Proximity of Health Care Center and Cervical Cancer Screening Uptake in Thailand
}

\author{
Kornnika Polrit ${ }^{1,3}$, Siriporn Kamsa-ard ${ }^{2}$, Chananya Jirapornkul ${ }^{1}$, Supannee \\ Promthet $^{1 *}$
}

\begin{abstract}
Background: Cervical cancer is one of the most common cancers among women worldwide, and in Thailand is the second most common cancer among women. In 2008, a national cervical cancer screening programme was implemented in Thailand, but coverage remains relatively low. Objectives: The purpose of the study was to investigate whether cervical cancer screening uptake is associated with the area of residency in Thailand. Materials and Methods: A case-control study was carried out in women aged 30 to 60 year-old, who live in Sikhiu district, Nakhon Ratchasima province, Thailand. Structured-questionnaires were used to interview 226 women (cases) who had attended cervical cancer screening in the last five years and 226 women (controls) who had not. Multiple logistic regression was used to investigate the association between the area of residency and cervical cancer screening uptake. Results: After controlling for parity, marital status and duration of hormonal contraceptive use, an association between the area of residence and cervical cancer screening uptake could not demonstrated $\left(\mathrm{OR}_{\text {adj }} 1.27,95 \% \mathrm{CI}\right.$ : 0.79, 2.04). Conclusions: We found no evidence to suggest remoteness to health care center led to lower cervical cancer screening uptake.
\end{abstract}

Keywords: Cervical cancer - screening - area of residency

Asian Pac J Cancer Prev, 16 (7), 2899-2902

\section{Introduction}

Cervical cancer is the third most common cancer in women worldwide. It is estimated that there are 528,000 new cases each year (Ferlay et al., 2013). The agestandardized incidence rate is 14.0 per 100,000 population and the mortality rate is 6.8 per 100,000 , approximately 266,000 women per year (Ferlay et al., 2013). In Thailand the annual incidence rate of cervical cancer in women in the year 2007 to 2009 was 16.7 per 100,000 population (Khuhaprema et al., 2013).

Cervical cancer screening has been shown to be an effective secondary prevention tool to find early abnormality in cervical cells (World Health Organization, 2013). It is reported that the coverage of cervical cancer screening in developed countries is $93.6 \%$, whereas in developing countries it is $44.7 \%$ (Gakidou et al., 2008). This is despite a much higher cervical cancer mortality rate in developing countries ( 8.3 per 100,000 population) compared to developed countries (3.3 per 100,000 population) (Ferlay et al., 2013).

The conception of setting up the organized cervical cancer screening in Thailand was initiated in 2002 and launched a few years later (Sriamporn et al., 2006). Women aged between 35 to 60 were invited to have cervical screening every 5 years, that is at ages $35,40,45$, 50,55 and 60 . However the coverage of screening in the target age group was still low in 2006 to 2009, at 27.7\% (Khuhaprema et al., 2012).

There are many factors associated with cervical cancer screening uptake. For instance, women who have been pregnant have considerably to have been shown to be screened more than woman who have not been pregnant. Other factors include receiving information from any source (Wongwatcharanukul et al., 2014) and higher family income (Budkaew and Chumworathayi, 2014). One potentially important factor is access, particulary geographical proximity to screening center. A study by Girgis et al. (1999) of cervical screening practices and beliefs of women from urban, rural and remote regions in New South Wales, Australia, found that women in remote areas have a higher rate of screening uptake than living women in urban areas $(\mathrm{OR}=1.86,95 \% \mathrm{CI}$ : 1.29-2.67). The present study aimed to investigate whether cervical cancer screening uptake is associated with the area of residency in a Thai context.

\section{Materials and Methods}

This was a population-based case-control study. The

${ }^{1}$ Department of Epidemiology, ${ }^{2}$ Department of Biostatistics and Demography, Faculty of Public Health, Khon Kaen University, Khon Kaen, ${ }^{3}$ District Health Office of Sikhiu, Nakhon Ratchasima Province, Thailand *For correspondence: supannee@kku.ac.th 


\section{Kornnika Polrit et al}

population were women aged 30 to 60 years old, who live in Sikhiu district, Nakhon Ratchasima province, Thailand; a population of 27,951 women (Region 9 Health Service Provider Office of Thailand, 2010). Cases were women who had received cervical cancer screening in the last 5 years (2009 to 2013) and controls were women who has not received cervical cancer screening in the same period. The sampling frame was obtained from the Sikhiu district health office and included a list of all women living in Sikhiu district. A simple random sample was taken of both cases and controls. The cervical cancer screening methods were the Pap smear and Visual Inspection Aids (Gaffikin et al., 2003; Deerasamee et al., 2007).

The sample size calculation was calculated using the formula for the unmatched case-control study (Schlesselman, 1982), the proportion of case and control was $1: 1$, at the 0.05 level of significance, a power of 0.80 and a minimal clinical effect of $\mathrm{OR}=2.20$. Women in urban area who did not attend the cervical cancer screening was
$11.5 \%$ (Martinez-Mesa et al., 2013). The initial sample size estimate was 190 . Then the calculation was adjusted by other variables, and multicolinearity was assumed to be 0.4 (Hsieh et al., 1998), resulting in a final sample of 226 per group. Structured-questionnaire was developed and applied in a pilot group of 30 women, to test for the knowledge.

Data collection was carried out by interviewing women during January to February 2014. All potential subjects (from the random sample) were invited to join the study and asked to provide informed consent . For those who were not available for the interview, other women who lived nearby and met the criteria were invited to replace that subject (This the case for about 5\%). There were 15 research assistants involved in this study and all were trained to minimized inter-observer bias. All data were double entered, and a check was then made for invalid or unusual observations.

The study effect, area of residency, was measured by

Table 1. Crude analysis and Multiple Logistic Regression Analysis between Factors and Cervical Cancer Screening Uptake

\begin{tabular}{|c|c|c|c|c|}
\hline Factors & $\begin{array}{l}\text { Cases } \\
\text { No }(\%)\end{array}$ & $\begin{array}{l}\text { Controls } \\
\text { No }(\%)\end{array}$ & $\begin{array}{l}\text { OR }_{\text {crude }} \\
(95 \% \mathrm{CI})\end{array}$ & $\begin{array}{l}\mathrm{OR}_{\text {adjusted }} \\
(95 \% \mathrm{CI})\end{array}$ \\
\hline \multicolumn{5}{|l|}{ Area of residency } \\
\hline Near to Health Care Center & $168(74.3)$ & $176(77.9)$ & 1 & 1 \\
\hline Far from Health Care Center & $58(25.7)$ & $50(22.1)$ & $1.22(0.79-1.87)$ & $1.27(0.79-2.04)$ \\
\hline \multicolumn{3}{|l|}{ Age (years) } & $X_{\mathrm{LRT}}^{2}=12.84 \mathrm{df}=2 \mathrm{p}=0.0016$ & $X_{\mathrm{LRT}}^{2}=9.02 \mathrm{df}=2 \mathrm{p}=0.0110$ \\
\hline $30-39$ & $50(22.1)$ & $76(33.6)$ & 1 & 1 \\
\hline $40-49$ & $100(44.3)$ & $66(29.2)$ & $2.30 * *(1.43-3.70)$ & $1.84 *(1.08-3.14)$ \\
\hline $50-60$ & $76(33.6)$ & $84(37.2)$ & $1.38(0.86-2.21)$ & $0.93(0.52-1.65)$ \\
\hline \multicolumn{3}{|l|}{ Number of pregnancy } & $X_{\mathrm{LRT}}^{2}=17.01 \mathrm{df}=4 \mathrm{p}=0.0019$ & $X_{\mathrm{LRT}}^{2}=8.27 \mathrm{df}=4 \mathrm{p}=0.0823$ \\
\hline 0 & $11(4.9)$ & $34(15.0)$ & 1 & 1 \\
\hline 1 & $26(11.5)$ & $35(15.5)$ & $2.30(0.98-5.36)$ & $1.87(0.72-4.81)$ \\
\hline 2 & $96(42.5)$ & $85(37.6)$ & $3.49 *(1.67-7.32)$ & $2.56 *(1.07-6.11)$ \\
\hline 3 & $63(27.9)$ & $49(21.7)$ & $3.97 * * *(1.83-8.63)$ & $3.19 *(1.27-8.00)$ \\
\hline$>3$ & $30(13.2)$ & $23(10.2)$ & $4.03 * *(1.69-9.63)$ & $3.37 *(1.25-9.06)$ \\
\hline \multicolumn{5}{|l|}{ Marital status } \\
\hline Single/Divorce/widow & $32(14.2)$ & $52(23.0)$ & 1 & 1 \\
\hline Married & $194(85.8)$ & $174(77.0)$ & $1.81 *(1.11-2.94)$ & $1.39(0.80-2.42)$ \\
\hline \multicolumn{3}{|c|}{ Duration of Hormonal contraceptives use a(years) } & $\begin{array}{l}X_{\text {LRT }}^{2}=5.81 \\
\mathrm{df}=4 \mathrm{p}=0.2135\end{array}$ & $\begin{array}{l}X_{\mathrm{LRT}}^{2}=57.97 \\
\mathrm{df}=4 \mathrm{p} \leq 0.0001\end{array}$ \\
\hline 0 & $50(24.3)$ & $60(29.0)$ & 1 & 1 \\
\hline $0.1-4.9$ & $40(19.4)$ & $48(23.2)$ & $1.00(0.57-1.76)$ & $0.72(0.38-1.33)$ \\
\hline $5.0-9.9$ & $43(20.9)$ & $46(22.2)$ & $1.12(0.64-1.96)$ & $0.76(0.40-1.45)$ \\
\hline $10-14.9$ & $31(15.0)$ & $27(13.0)$ & $1.38(0.73-2.61)$ & $0.82(0.41-1.67)$ \\
\hline$\geq 15.0$ & $42(20.4)$ & $26(12.6)$ & $1.94 *(1.05-3.59)$ & $1.18(0.60-2.33)$ \\
\hline \multicolumn{3}{|l|}{ Contraceptives use } & $X_{\mathrm{LRT}}^{2}=2.79 \mathrm{df}=2 \mathrm{p}=0.2480$ & - \\
\hline Never & $24(10.6)$ & $36(15.9)$ & 1 & \\
\hline $\begin{array}{l}\text { None Hormonal contraceptives } \\
\text { (Sterilization, Intrauterine devic }\end{array}$ & $\begin{array}{c}26(11.5) \\
\text { s, Condom) }\end{array}$ & $24(10.6)$ & $1.63(0.76-3.47)$ & \\
\hline \multicolumn{5}{|c|}{ Hormonal contraceptives (Oral, Injection, Implants) } \\
\hline & $176(77.9)$ & $166(73.5)$ & $1.59(0.91-2.78)$ & \\
\hline \multicolumn{4}{|l|}{ Education } & - \\
\hline No education/Primary & $144(63.7)$ & $139(61.5)$ & 1 & \\
\hline Secondary/Post-secondary & $82(36.3)$ & $87(38.5)$ & $0.91(0.62-1.33)$ & \\
\hline \multicolumn{4}{|c|}{ Knowledge regarding cervical cancer (total 15 scores) } & - \\
\hline$<12$ scores & $141(62.4)$ & $143(63.3)$ & 1 & \\
\hline $12-15$ scores & $85(37.6)$ & $83(36.7)$ & $1.04(0.71-1.52)$ & \\
\hline \multicolumn{3}{|l|}{ Occupation } & $X_{\mathrm{LRT}}^{2}=0.26 \mathrm{df}=2 \mathrm{p}=0.8785$ & - \\
\hline Farming & $82(36.3)$ & $80(35.4)$ & 1 & \\
\hline Housewife/Unemployed & $40(17.7)$ & $37(16.4)$ & $1.05(0.61-1.82)$ & \\
\hline Business/ Employee /Civil service & $104(46.0)$ & $109(48.2)$ & $0.93(0.62-1.40)$ & \\
\hline
\end{tabular}


the distance from the participants house to the health care service center. This variable was then categorized into 2 groups; nearer to Health Care Center and farther from Health Care Center. Each of the 16 health care centers in the Sikhiu district have a certain number of households under their responsibility. The measurement of distance between place of residence and the local health care center was performed using GPS based on the Haversine formula (Sinnott, 1984). The maximum distant from an individual house to its health care service center were combined (across health care center catchments) and the mean maximum distance was calculated, a value of 29.39 kilometers. The mean distance of households to their health care center was 14.695 kilometers, and it was the mean distance that was used as a cut point for the nearer and farther categories.

The association between the cervical cancer screening uptake and potential risk factors were evaluated using odds ratios (ORs) with their $95 \%$ confidence intervals. Both crude and adjusted ORs were obtained using binary logistic regression (area of residency, age, marital status, parity, contraception). Factors included in the multivariable model (backward elimination) were those found to be potentially associated with the cervical cancer screening uptake in the bivariate analysis $(\mathrm{p}<0.25)$. Variables not found to be associated with the cervical cancer screening uptake in the bivariate analysis, but which are reported in the literature as having an important role in cervical cancer screening uptake, were forced into the model. All statistical analyses were performed using STATA version 10 . Statistical significance was set at a level of 0.05 .

The research was approved by the Khon Kaen University Ethics Committee for Human Research (Reference no. HE 562258).

\section{Results}

In total, 452 women were include in the present study (226 cases ; 226 controls). Generally the average age of both cases and controls were similar $\left(\overline{\mathrm{x}}_{\text {cases }}=45.8 ; \mathrm{SD}_{\text {cases }}=7.8\right.$; $\left.\overline{\mathrm{X}}_{\text {controls }}=44.8 ; \mathrm{SD}_{\text {controls }}=9.8\right)$. The average monthly income of both group was comparable $\left(\bar{x}_{\text {cases }}=10,428.9\right.$ Baht; $\mathrm{SD}_{\text {case }}=8,944.7 ; \overline{\mathrm{x}}_{\text {controls }}=9,870.6$ Baht; $\mathrm{SD}_{\text {controls }}=8,174.6$ ) and the most common employment of both group was agriculture $($ cases $=36.3 \%$; controls $=35.4 \%$ ). There was some difference in the marital status of the two groups with a higher proportion of cases being in the married/ living together category $($ cases $=85.8 \%$; controls $=77 \%$ )

The results of the bivariate and multivariable analysis are provided in Table 1. The results show that geographical proximity to screening center could not be shown to be associated with screening uptake at either the crude level $\left(\mathrm{OR}_{\text {crude }}=1.22, \mathrm{p}=0.377,95 \% \mathrm{CI}\right.$ : $\left.0.79,1.87\right)$ or after adjusting for potential confounders $\left(\mathrm{OR}_{\mathrm{adj}}=1.27, \mathrm{p}=0.331\right.$, $95 \% \mathrm{CI}: 0.79,2.04)$. It is apparent that adjustment for the marginal difference in the demographics of the two groups had little effect of the estimate of the geographical proximity effect $\left(\mathrm{OR}_{\text {crude }}=1.22 v s \mathrm{OR}_{\text {adj }}=1.27\right)$

We did identify other important factors associated with screening uptake. The odds of previous screening was higher in women who had had two $\left(\mathrm{OR}_{\mathrm{adj}}=2.56, \mathrm{p}=0.035\right.$, 95\%CI: $1.07,6.11)$, three $\left(\mathrm{OR}_{\mathrm{adj}}=3.19, \mathrm{p}=0.013,95 \% \mathrm{CI}\right.$ : $1.27,8.00)$, or four or more $\left(\mathrm{OR}_{\text {adj }}=3.37, \mathrm{p}=0.016,95 \% \mathrm{CI}\right.$ : $1.25,9.06$ ) previous pregnancies (Table 1). Age was also significantly associated with screening uptake with women in the 40-49 age group more likely to have been screened $\left(\mathrm{OR}_{\mathrm{adj}}=1.84, \mathrm{p}=0.025,95 \% \mathrm{CI}: 1.08,3.14\right)$ compared to the youngest group (30-39 years old). However women in the oldest age group could not be shown to be more likely to have been screened $\left(\mathrm{OR}_{\mathrm{adj}}=0.93, \mathrm{p}=0.803,95 \% \mathrm{CI}\right.$ : $0.52,1.65)$. Marital status was shown to be associated of screening uptake in the bivariate analysis $\left(X_{\text {LRT, marital }}^{2}=5.90\right.$ $\mathrm{df}=1, \mathrm{p}=0.015$ ) but after adjusted confounders (most probability age) this effect could not be shown to be associated with screening uptake $\left(X_{\text {LRT, marital }}^{2}=1.36 \mathrm{df}=1\right.$, $\mathrm{p}=0.244)$.

\section{Discussion}

The effect of distance from screening center on cervical cancer screening uptake has received little attention. With the exception of an Australia study on geographical proximity, no other study has focused on the effect of proximity, and to best of our knowledge, never in the Asian context. We found no evidence to suggest that living farther away from the screening center represents a barrier to cervical cancer screening.

The organized cervical cancer screening programme provided by the Ministry of Public Health, Thailand, has shown to be quite effective (Khuhaprema et al., 2012). A study by Gaffikin and others (2003) identified the mode of transport to health care services were walking, motorcycle and bicycle and the time spent reaching the health care center range from 1 minute to 2 hours. We felt that long transportation time may represent a barrier to screening uptake, but this does not appear to be the case. Our findings are in alignment with findings of studies in developed countries (Celaya et al., 2010; Wilson et al., 2011; Brewer et al., 2012) but a study by St-Jacques and colleages (2013) found that women closer to their screening center were more likely to get breast screening and a study by Girgis and others (1999) found the opposite: women in remote Australia were more likely to be screened for cervical cancer than women living in urban area. Whether there is a difference in the perception of the importance of getting breast screening compared to cervical cancer is something that needs future investigation.

The present study did have some potential limitations. First, as a case-control study there is always the potential for recall bias. This may be potentially important in this study, where there may have been some lack of understanding about the procedures patients undergo; some woman may not know they have been screened.

A second, and potentially important limitation of this study is that it was conducted in women from a single district. Whether our findings are generalizable to Thai women, in particular, or Asian women, in general, is not clear. Only future study of the impact of distance from screening center on screening uptake will answer this question. It is clear more work need to be done. However this is the first study in Asia to address whether distance of 


\section{Kornnika Polrit et al}

abode from screening center has an impact on screening uptake. Our results suggest that proximity to screening centre does not represent a barrier, and that it is other factors, such as younger age, that should be the focus of public health interventions. However, studies with wider coverage are needed to get a definitive answer to this question.

\section{Acknowledgements}

The authors would like to thank the participants in the study. We are grateful for the Khon Kaen University Graduate Research Fund for Academic Year 2013 for financial support for this research. Thanks are due to Dr.Cameron Hurst for his advice and assistance in writing this paper.

\section{References}

Brewer N, Pearce N, Day P, Borman B (2012). Travel time and distance to health care only partially account for the ethnic inequalities in cervical cancer stage at diagnosis and mortality in New Zealand. Aust NZ J Public Health, 36, 335-42.

Budkaew J, Chumworathayi B (2014). Factors associated with decisions to attend cervical cancer screening among women aged 30-60 years in Chatapadung contracting medical unit, Thailand. Asian Pac J Cancer Prev, 15, 4903-7.

Celaya MO, Berke EM, Onega TL, et al (2010). Breast cancer stage at diagnosis and geographic access to mammography screening (New Hampshire, 1998-2004). Rural Remote Health, 10, 1361.

Deerasamee S, Srivatanakul P, Sriplung H, et al (2007). Monitoring and evaluation of a model demonstration project for the control of cervical cancer in Nakhon Phanom province, Thailand. Asian Pac J Cancer Prev, 8, 547-56.

Ferlay J, Soerjomataram I, Ervik M, et al (2013).GLOBOCAN 2012 v1 .0, cancer incidence and mortality worldwide: IARC cancerbase No. 11 [Internet]. Lyon, France: international agency for research on cancer. Available from: http:// globocan.iarc.fr, accessed on 22 June 2014.

Gaffikin L, Blumenthal PD, Emerson M, Limpaphayom K (2003). Safety, acceptability, and feasibility of a single-visit approach to cervical-cancer prevention in rural Thailand: a demonstration project. Lancet, 361, 814-20.

Gakidou E, Nordhagen S, Obermeyer Z (2008). Coverage of cervical cancer screening in 57 countries: Low average levels and large inequalities. PLoS Med, 5, 132.

Girgis A, Bonevski B, Perkins J, Sanson-Fisher R (1999).Selfreported cervical screening practices and beliefs of women from urban, rural and remote regions. J Obstet Gynaecol, 19, 172-9.

Hsieh FY, Bloch DA, Larsen MD (1998). A simple method of sample size calculation for linear and logistic regression. Statis Med, 17, 1623-34.

KhuhapremaT, Attasara P, Srivatanakul P, et al (2012). Organization and evolution of organized cervical cytology screening in Thailand. Int J Gynaecol Obstet, 118, 107-11.

Khuhaprema T, Attasara P, Sriplung H, et al (2013). Cancer in Thailand Vol. VII, 2007-2009. Bangkok: National Cancer Institute.

Martinez-Mesa J, Werutsky G, Campani RB, Wehrmeister FC, Barrios CH (2013). Inequalities in Pap smear screening for cervical cancer in Brazil. Preventive Medicine, Available from: http://dx.doi.org/10.1016/j.ypmed.2013.06.026, accessed on 22 June 2014

Region 9 Health Service Provider Office of Thailand (2010). The population of women aged 30 to 60 years old, Sikhiu district [Internet]. Nakhon Ratchasima province, Thailand. Available from: http://164.115.22.73/k9/splan/?content=p4\&r=p4. Reports.Amp\&pvcode $=30 \&$ ampcode $=3020$, accessed on 22 December 2014.

Schlesselman JJ (1974). Sample size requirements in Cohort and Case-control studies of disease. Am J Epidemiol, 99, 381-4.

Sinnott RW (1984). Virtues of the haversine. Sky Telescope, 68, 159 .

Sriamporn S, Khuhaprema T, Parkin M (2006). Cervical cancer screening in Thailand: an overview. J Med Screen, 13, 39-43.

StataCorp LP (2007). Stata Release 10: User's guide. College Station TX: Stata Press.

St-Jacques S, Philibert MD, Langlois A, et al (2013). Geographic access to mammography screening centre and participation of women in the quebec breast cancer screening Programme. $J$ Epidemiol Community Health, 67, 861-7.

Wilson RT, Giroux J, Kasicky KR, et al (2011). Breast and cervical cancer screening patterns among American Indian women at IHS clinics in montana and wyoming. Public Health Rep, 126, 806-15.

Wongwatcharanukul L, Promthet S, Bradshaw P, Jirapornkul C, Tungsrithong N (2014). Prevalence of high risk human papillomavirus infection with different cervical cytological features among women undergoing health examination at the national cancer institute, Thailand. Asian Pac J Cancer Prev, 15, 3753-6.

World Health Organization (2013).WHO guidance note: Comprehensive cervical cancerprevention and control:a healthier future for girls and women. Geneva: WHO. 